\title{
Upcycling: um novo caminho para a moda sustentável
}

\author{
Upcycling: A new path to sustainable fashion design
}

MORELLI, Graziela; Doutora; Universidade do Vale do Itajaí grazielamorelli@univali.br

ENDER, Jaqueline; Bacharel; Universidade do Vale do Itajaí jaque-rich@live.com

\section{Resumo}

A indústria têxtil descarta toneladas de resíduos têxteis no lixo comum, e as roupas usadas pelos consumidores também têm esse destino. A pesquisa apresenta o processo de upcycling como ferramenta sustentável que amplia o ciclo de vida e agrega valores estéticos, funcionais e mercadológicos ao produto. $\mathrm{O}$ objetivo geral é analisar este processo na área do design como alternativa para o desenvolvimento de produtos de moda mais sustentáveis. Fez-se uso do método de pesquisa cientifica com objetivo exploratório, abordagem qualitativa e pesquisa bibliográfica. Pôde-se perceber que, entre as alternativas apresentadas para ampliação do ciclo de vida e redução de resíduo têxtil, o upcycling mostra-se como uma ferramenta viável.

Palavras Chave: indústria têxtil; sustentabilidade; upcycling.

\begin{abstract}
The textile industry discards tons of textile waste in the trash, and the clothes worn by consumers also have that fate. The research presents the upcycling process as a sustainable tool that extends the life cycle and adds aesthetic, functional and market values to the product. The objective is to analyze this process in design as an alternative for the development of more sustainable fashion products. The method of scientific research used is with exploratory purpose, qualitative approach and bibliographic research. It can be seen that, among the alternatives presented for extending the life cycle and reduction of textile waste, upcycling is shown as a viable tool.
\end{abstract}

Keywords: textile industry; sustainability; upcycling.

No mercado de moda atual, as peças se tornam obsoletas rapidamente, devido a efemeridade da moda e ao comportamento dos consumidores e do mercado. $\mathrm{O}$ ciclo dos produtos de moda está cada dia mais curto. Uma peça de roupa deixa de ser desejo do consumidor e é descartada, muitas vezes antes mesmo de perder sua qualidade necessária para uso.

Gwilt (2014, p.138) acredita que "as roupas são jogadas fora por muitas razões: podem estar desgastadas pelo uso ou estarem fora de moda, talvez por não servirem mais ou por simplesmente não terem mais boa aparência". Levando em conta esses motivos é possível 
perceber que, mesmo sendo descartada, uma peça de roupa ainda pode ter aspectos de funcionalidade e, em certas partes, um material de qualidade. Mas essa avaliação não é feita pelo consumidor e a peça acaba indo para o lixo doméstico mesmo já existindo outros caminhos para descarte, como a reciclagem de tecidos.

O descarte de peças usadas e sobras de produção têxtil destinados ao lixo, causam grandes problemas ambientais. No Brasil, segundo a Associação Brasileira da Indústria Têxtil e de Confecção (ABIT), cerca de 170 mil toneladas de lixo têxtil são descartadas por ano, e apenas $10 \%$ desse valor destina-se a um local correto, onde são separados e inseridos em novos processos de produção. colocar fonte, autor ou pelo menos data

O material descartado serve como matéria prima para outros setores da indústria, como automobilístico, reciclagem e até mesmo para o próprio setor têxtil, o qual busca novas formas de produção visando a sustentabilidade. Os $90 \%$ restantes são descartados no lixo comum, e se destinam a aterros sanitários, gerando poluição no solo e no ar além de demorar muitos anos para se decompor.

Para a mudança desse cenário é preciso uma revisão no princípio do planejamento dos produtos e no descarte. O design deve se adaptar e buscar novas tecnologias para que os produtos sejam mais duráveis e sua produção gere menos impacto no meio ambiente (BEZERRA; MATOS; PESSOA, 2011).

De acordo com Camargo et al. (2015, p.2), o conceito de sustentabilidade "consiste em desenvolver práticas e/ou usos, que buscam minimizar as ações nocivas ao meio ambiente". Baseado na necessidade de mudar a concepção de um produto, começam a surgir novos caminhos que visam um freio no consumo e uma oportunidade para sustentabilidade, como o slow fashion e o processo de upcycling.

Há uma obrigatoriedade em se pensar sustentável nos tempos em que vivemos. Lopes, Padilha e Schulte (2014, p.87) destacam que "diante do volume de resíduos têxteis das confecções de vestuário e das roupas descartadas pelo consumidor, não é mais possível ignorar os problemas gerados pelo excesso de produção e consumo na área da moda". A procura de um caminho para tornar-se um produto ou o processo pelo qual este produto é feito de forma mais natural e que não fira direitos humanos e ecológicos se torna um campo possível para um processo inovador.

Esta pesquisa procura levantar aspectos relacionados ao grande descarte produzido pela indústria de confecção e de moda e apresenta o seguinte questionamento como ponto de partida: de que forma o upcycling pode contribuir para o design de moda mais sustentável?

Emidio e Souza (2015) definem que o conceito do upcycling gira em torno da proposta de alongar o ciclo de vida de um produto que foi descartado, quando adquire uma nova forma, função e agrega valor mercadológico ao produto. Assim, o objetivo geral da pesquisa é analisar o processo de upcycling na área do design como alternativa para o desenvolvimento de produtos de moda mais sustentáveis. Para alcançar o objetivo geral é necessário: reconhecer as características do upcycling como processo de desenvolvimento de novos produtos; comparar aspectos positivos e negativos da aplicação do upcycling na indústria do vestuário em relação a outros processos que visam a sustentabilidade e identificar exemplos de projetos de upcycling no design de moda.

Toda essa análise requer pesquisas para o reconhecimento das características do processo de upcycling $e$, a fim de justificar o processo como uma ferramenta sustentável funcional, é fundamental comparar aspectos positivos e negativos da aplicação do processo na indústria do vestuário em relação a outros processos que visam a sustentabilidade como materiais 
sustentáveis, alugueis e trocas de produtos, reciclagem, sistemas de coleta e devolução. Por fim, para fechar a análise de maneira coesa, identificar exemplos de projetos de upcycling na área de design de moda que defendam o processo como ampliador do ciclo de vida do produto, reforçam a preocupação em entender como ele já está sendo aplicado.

A pesquisa com foco no upcycling visa contribuir para estudos relacionados a uma possível aplicação deste processo em projetos de design e indústrias têxteis. Para solucionar a problemática e alcançar esses objetivos da pesquisa, definiu-se o objetivo da pesquisa como exploratório e de abordagem qualitativa.

\title{
Design de moda e sustentabilidade
}

O design se refere a criação de um produto, mas além do produto abrange o desenvolvimento de um projeto. Moura define que:

\begin{abstract}
Design significa ter e desenvolver um plano, um projeto, significa designar. É trabalhar com a intenção, com o cenário futuro, executando a concepção e o planejamento daquilo que virá a existir. Criar, desenvolver, implantar um projeto, o design significa pesquisar e trabalhar com referências culturais e estéticas, com o conceito da proposta. É lidar com a forma, com o feitio, com a configuração, a elaboração, o desenvolvimento e o acompanhamento do projeto (VALESE et al., 2003, p.118).
\end{abstract}

Sendo assim, o design trabalha um projeto para o futuro, em que há objetivos a serem alcançados e conceitos a serem seguidos, delineados por um planejamento e feito por um desenvolvimento acompanhado da figura do designer a fim de criar um produto. O contexto cultural, econômico, social e ambiental devem servir de base para o designer em seus projetos, considerando seus impactos e contribuições.

Segundo Lipovetsky (2009), a moda é um mecanismo social que gera mudanças de tempos em tempos na sociedade. Essas mudanças são proferidas pelo capricho da vida coletiva, sem depender de um objeto em questão, ou seja, a moda não depende do produto, mas o produto e seu sucesso depende da moda. Se pensarmos dessa forma, fica evidenciado que o consumo é ditado pela sociedade, mas o design e a indústria de manufatura são os responsáveis pela oferta de produtos.

Em nível nacional, segundo dados apresentados pela Associação Brasileira da Indústria Têxtil e de Confecção (ABIT), no ano de 2014 foram produzidas 9,2 bilhões de peças de roupa. Além do valor de produção, o Brasil importa mais 3\% de peças de roupa. Considerando a população brasileira, esse dado numérico significa uma média de 48 peças de roupa por consumidor no período de um ano. Este dado mostra que a sociedade brasileira está consumindo cada vez mais. Dados do Ibope demonstram que cada cidadão encerrou 2013 com gasto médio de R $\$ 786$ em roupas e acessórios, valor $17 \%$ maior do que os $\mathrm{R} \$ 670$ registrados em 2012.

Se o consumo de roupas cresce rapidamente, as indústrias têxteis produzem mais e esse estilo de vida consumista afeta o planeta. Para Fletcher e Grose (2011, p. 13), os impactos das indústrias têxteis sobre o meio ambiente abrangem "mudanças climáticas, poluição química, perda da biodiversidade, uso excessivo ou inadequado de recursos não renováveis, geração de resíduos, efeitos negativos sobre a saúde humana, efeitos sociais nocivos para as comunidades produtoras". Esses impactos demonstram que é insustentável continuar produzindo da 


\section{GAMPI}

maneira atual. Uma maneira de mudar esse cenário é diminuir a produção de produtos e, para isso, é preciso estender o ciclo de vida das roupas (EMIDIO e SOUZA, 2015). Para essa ação é necessário entender mais sobre o ciclo de vida, mas anterior a isto, é primordial compreender a sustentabilidade.

A sustentabilidade está relacionada a "três áreas relevantes: a sociedade, que deve focar o direito de propriedade social; o meio ambiente, que por sua vez, deve focar a estabilidade ecológica; e a economia, cujo foco deve estar centrado na viabilidade econômica" (GWILT, 2014, p.22). Esses aspectos estão relacionados às práticas sustentáveis que buscam melhorar as condições de vida da sociedade, minimizar as ações nocivas ao meio ambiente e tornar os processos financeiramente viáveis.

O ciclo de vida de um produto é um conjunto de etapas que um produto percorre para cumprir sua função na cadeia produtiva. O ciclo de vida de uma roupa de moda é divido em cinco etapas: design, produção, distribuição, uso e fim da vida (GWILT, 2014, p.32). Em cada etapa são desenvolvidas diversas atividades que compreendem o processo. No design o produto é projetado e os materiais e processos são escolhidos; na produção são criados os moldes, peças pilotos e os produtos são construídos; na distribuição os produtos são levados das empresas até as lojas e aos consumidores; no uso o consumidor veste, lava e interfere no produto, seja um conserto, reforma ou qualquer tipo de desgaste e, no fim da vida o produto é descartado, reutilizado ou reciclado. As etapas e as atividades efetuadas no ciclo de vida de um produto de moda são retratadas na Figura 1, em forma de fluxograma de ciclo.

Figura 1: Etapas do ciclo de vida

\section{CICLO DE VIDA}

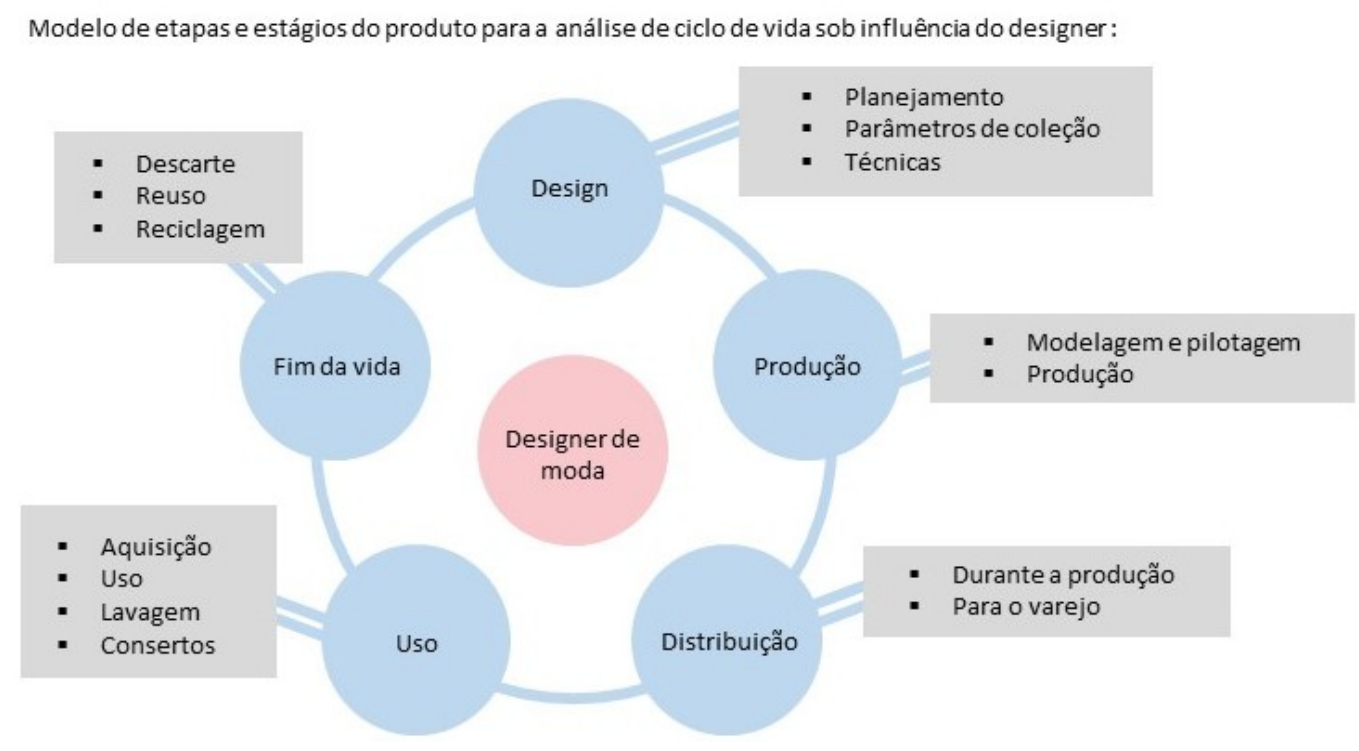

Fonte: Fluxograma adaptado pelo autor a partir de GWILT (2014)

Além do descarte do produto no fim da sua vida útil, durante o processo de produção desse produto há uma geração de resíduos. Essas sobras de matéria prima normalmente não têm valor para a indústria e acabam virando lixo. Segundo Lara, Carneiro e Fabri (2015, p. 04):

O processo de confecção de uma roupa gera sobras de tecidos, que são incinerados 6o GAMPI Plural, 2017, Joinville, SC. 
ou descartados em aterros sanitários depois que a sua vida útil se esgota, bem como peças confeccionadas que chegam ao final do seu ciclo de vida, seja na cadeia do varejo ou nas mãos do consumidor.

Portanto, o degaste ambiental de um produto sob a natureza não se refere apenas ao material usado no produto, mas sim ao processo pelo qual ele passou. Então, além de ampliar o ciclo de vida de um produto, é necessário diminuir a quantidade de resíduos gerados durante a produção e encontrar uma maneira de descarte menos poluente, tanto com relação ao produto como dos seus resíduos. Para Salcedo (2014, p.39) "o verdadeiro desafio é repensar e redefinir a forma de desenhar, produzir, distribuir e utilizar as peças".

Quando relacionamos o design de moda a sustentabilidade, o desafio do designer é gerenciar o contexto sócio-econômico-ambiental de maneira responsável a fím de adotar uma abordagem realmente sustentável para o projeto (CAVALCANTI e SANTOS, 2015). A fim de fazer um design para a sustentabilidade, é necessário utilizar processos de produção mais limpos e mudar o comportamento do consumidor sobre a maneira de consumir e usar o produto.

Com base nisso, o designer de moda pode incluir estratégias de sustentabilidade em qualquer etapa do projeto e do ciclo de vida do produto. Gwilt (2014, p .20) aponta que uma estratégia de design sustentável é considerada "uma abordagem estruturada que pode ser empregada por um designer com o objetivo de colaborar na redução dos impactos ambientais e/ou sociais associados à produção, ao uso e ao descarte". Dessa forma, é possível trabalhar todos os contextos da sustentabilidade.

A partir desse ponto, surgem várias estratégias de design sustentável. Essas estratégias podem ser inseridas na análise de ciclo de vida, no intuito de projetar as etapas do produto desde de sua concepção até o seu descarte. As inserções das estratégias no ciclo de vida de um novo produto estão descritas na Figura 2.

Figura 2: Estratégias de design sustentável

\section{ESTRATÉGIAS}

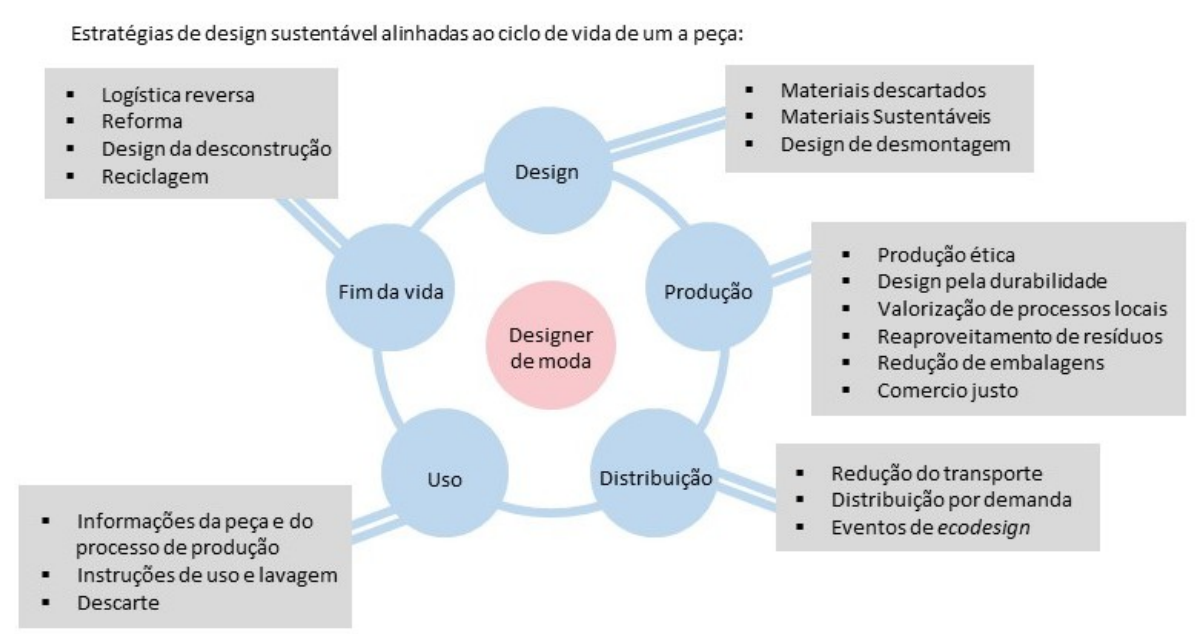

Fonte: Fluxograma adaptado pelo autor a partir de GWILT (2014)

As estratégias de sustentabilidade apontadas no ciclo de vida, apresentadas na figura 2, são modulares, podem ser adotadas em diferentes etapas e adaptadas para cada tipo de projeto. Elas se referem a base de matéria prima, planejamento de design, técnicas de produção e 
distribuição, informações de uso e formas de descarte. Na pesquisa em questão, propõe-se apresentar o processo de upcycling, como ferramenta estratégica de design sustentável, aplicada no fim da vida de um produto, para que o resultado desse processo seja um novo ciclo de vida, cada vez mais longo, e com inclusão de estratégias sustentáveis durante o processo, a fim de criar um produto de moda mais sustentável. O processo de upcycling e análise dessa inclusão é apresentado na próxima subseção.

\section{O processo de upcycling}

Com o consumo desenfreado, muitos produtos são descartados diariamente. Quando ocorre um descarte, significa que o produto chegou ao fim da sua vida útil, ou seja, ele não desempenha mais a função a qual foi proposto a executar. Alguns materiais já são separados e destinados para a reciclagem, como papel, vidro, plástico, metal e lixo eletrônico, mas alguns materiais como tecidos, borrachas, cerâmicas e madeiras ainda não têm um destino definido como correto.

Objetos como roupas, aviamentos, artigos de casa, pneus, usinagens, rolamentos, móveis, lixo eletrônico e lixo industrial levam centenas de anos para se decompor, em aterros e lixões, mas podem ser recuperados e transformados. Para Cavalcanti e Santos (2015), recuperar esses materiais que chegaram no fim da sua vida é possível e esse processo é chamado de upcycling, que transforma e reaproveita materiais, sem perder sua composição e aspecto físico original, mas aumentando seu valor comercial.

A palavra upcycling surgiu na língua inglesa com a junção de duas palavras: 'up' e 'recycling'. Seu conceito consiste em um processo ou técnica de transformar descartes e materiais sem uso em novos produtos, sem que o material seja incinerado (LOPES, PADILHA e SCHULTE, 2014).

Segundo a jornalista Andréa Vialli (2010), especializada em sustentabilidade e meio ambiente, o processo de upcycling consiste em reinserir no processo produtivo materiais descartados para criar novos produtos, sem submeter o material a processos químicos ou físicos nocivos a sociedade e natureza. Cavalcanti e Santos (2015) acrescentam que o upcycling é uma abordagem consciente e criativa que cria novos produtos a partir da reutilização de materiais.

$\mathrm{O}$ processo de upcycling atua sobre o material descartado sem depreciá-lo, aumenta o aproveitamento, altera aspectos estéticos e funcionais, agrega valor e prolonga a vida útil. $\mathrm{O}$ upcycling pode ser aplicado de modo sucinto, propondo pequenas mudanças, melhorias e detalhes decorativos, ou de modo extenso, criando novos produtos. Somado a isso, Vinken (2005) defende que todo produto proveniente de um material de descarte, é único e exclusivo. De acordo com Gwilt (2014), um ponto importante do processo de upcycling é a escolha dos materiais. É necessário efetuar uma triagem, separando componentes úteis e inúteis e, em alguns casos, será preciso descontruir o material, e prepará-lo para a produção, antes que seja utilizado. Estas e outras etapas do processo podem ser levantadas na projeção de análise de ciclo de vida de um produto proveniente de upcycling, apresentado na Figura 3.

Figura 3: Etapas no processo de upcycling 
PROCESSO

Aplicação do processo de upcycling descrita nas etapas do ciclo de vida com aplicação de estratégias sustentáveis:

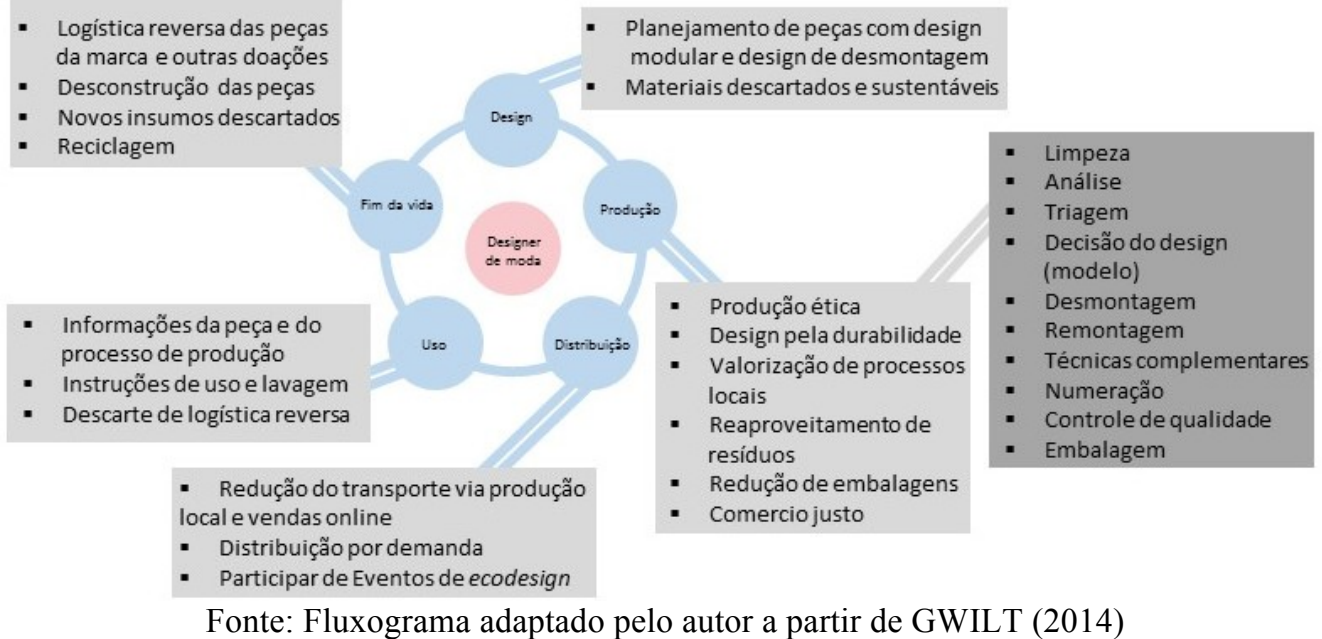

Além da sequência de etapas para o processo de upcycling, a Figura 3 demonstra possíveis inserções de estratégias sustentáveis em todas as etapas do processo da cadeia produtiva.

O design modular é flexível pois interpreta um produto em partes menores, que sozinhas são módulos e unidos se transformam em um produto. Esses módulos são criados de maneira independente, e podem fazer parte de vários tipos de produtos, não pertencendo a apenas um modelo (GWILT, 2014). O design de desmontagem visa a sustentabilidade, tratando de criar um produto pensando primeiro em como desmontá-lo (SALCEDO, 2014).

Esse tipo de design é muito utilizado em desenvolvimentos de embalagens, para facilitar a reciclagem do material, mas no caso da moda, ele pode servir para a reutilização do material e a aplicação do processo de upcycling. A soma desses dois tipos de design, modular e de desmontagem, gera possibilidades para aplicação do processo de upcycling em escala industrial, pois a produção dos módulos equivale a diversos produtos, e a desmontagem introduz a reutilização dos materiais.

A segunda etapa do ciclo de vida do produto é a produção e nela podem ser utilizadas as propostas: o design pela durabilidade que, para Salcedo (2014), defende uma confecção ou produção com altos níveis de qualidade, sendo assim os processos são revisados em cada etapa, feitos da maneira indelével, e a produção ética, que respeita de maneira profissional a moral dos indivíduos e garante condições dignas de trabalho.

A valorização de processos locais, distribuição por demanda e redução dos transportes são estratégias pertencentes a terceira etapa do processo, a distribuição que, na visão de Gwilt (2014), visam diminuir o deslocamento dos produtos por espaços territoriais e utilizar meios de transporte menos poluentes.

$\mathrm{Na}$ quarta etapa o grande responsável é o consumidor. Para que ele use e conserve o produto de maneira adequada é necessário informá-lo sobre o desenvolvimento e produção da peça, as instruções de uso, lavagem, armazenamento, e até mesmo, como ele deve efetuar o descarte. $\mathrm{O}$ descarte está relacionado a quinta etapa do ciclo. $\mathrm{O}$ fim da vida do produto pode ser o início de um novo processo, portanto, a logística reversa é fundamental. Do ponto de vista de Lopes, Padilha e Schulte (2014) a logística reversa facilita o retorno do produto para a remanufatura, e um produto que tem um destino de retorno adequado é rapidamente remetido novamente ao 
mercado. Esse processo de retorno do material é um sistema de ciclo fechado, também conhecido como economia circular. O termo "descreve o processo de constante reuso do material, sem permitir que ele entre no fluxo de resíduos" (GWILT, 2014, p. 152), mas abrange, além do uso de descartes, a possibilidade de reciclagem.

As estratégias sustentáveis descritas são algumas opções para a vinculação do upcycling em um processo de desenvolvimento de produtos de moda sustentáveis. Mas como saber se o processo de upcycling é uma solução eficaz para o desenvolvimento de produtos de moda mais sustentáveis? Para responder essa pergunta serão comparados, na subseção seguinte, pontos positivos e negativos de outros processos de sustentabilidade em relação ao upcycling.

\section{Estratégias de sustentabilidade $X$ Upcycling}

O acúmulo de roupas descartadas e a poluição causada pela cadeia têxtil não iniciou somente uma mudança no final do ciclo de vida dos produtos, mas também no início. Hoje há muitas estratégias para desenvolver produtos de moda mais sustentáveis. Essas estratégias de sustentabilidade podem ser aplicadas em qualquer etapa do ciclo de vida do produto.

Para a comparação com o upcycling, optou-se por estratégias de sustentabilidade em diferentes etapas do ciclo de vida. Na etapa de design, a estratégia de materiais mais sustentáveis; na etapa de uso, as estratégias de consertos, alugueis e/ou trocas de produtos e; na etapa de fim da vida, a reciclagem e os sistemas de coleta e devolução.

Antes de levantar as informações dessas outras estratégias, ressaltam-se os pontos positivos do upcycling como: uma vasta opção de materiais descartados, junção de novos processos de fabricação, e elevação do valor mercadológico. Por outro lado, algumas partes do processo são totalmente manuais, demoradas e exigem muita atenção e qualidade. Esses pontos podem aumentar consideravelmente o valor do processo.

Uma das primeiras etapas do desenvolvimento de um produto é a escolha dos materiais. No design de moda os tecidos têm grande influência na função e na estética do produto. Segundo Salcedo (2014), como nenhuma fibra pode ser considerada totalmente sustentável, as fibras que menos agridem o ambiente e a sociedade, são chamados de fibras de menor impacto. As fibras de menor impacto podem ser classificadas em naturais, artificiais e sintéticas e em ecológicas, recicladas, biopolímeros e naturais de menor impacto.

As fibras naturais de menor impacto são ecológicas, recicladas e naturais de menor impacto e alguns exemplos disponíveis no mercado são: o algodão orgânico, algodão oriundo de comércio justo, algodão reciclado, linho, urtiga e cânhamo. O comércio das fibras de algodão de menor impacto é certificado e segue rigorosos padrões de comércio justo e práticas de cultivo de menor impacto. As últimas três opções: linho, urtiga e cânhamo, são provenientes de plantas de cultivo rápido, que não necessitam irrigação e requerem pouco uso de pesticidas e fertilizantes (ANICET e RUTHSCHILLING, 2012).

As fibras artificiais de menor impacto são classificadas em ecológicas, pois são desenvolvidas a partir de madeiras de plantações sustentáveis, que não necessitam irrigação, fertilizante, pesticidas, e são cultivadas de forma natural. Além da origem mais sustentável, as novas fibras artificias de menor impacto como o tencel e lenzing modal, apresentam melhoras no processo de fabricação e nos aspectos funcionais da fibra (SALCEDO, 2014).

As fibras sintéticas de menor impacto são recicladas e biopolímeros. O poliéster reciclado é produzido de resíduos e descartes de poliéster, e os biopolímeros são materiais sintéticos criados de matérias-primas renováveis como milho e cana de açúcar (SALCEDO, 2014). 
Em análise sobre a utilização das fibras de menor impacto, é possível destacar pontos positivos como a melhoria da fertilidade do solo, a restrição da utilização de recursos finitos, a redução do uso da água, que evita poluição da mesma, e do uso de pesticidas, a diminuição da emissão de gás carbônico e do uso de energia, a minimização os riscos dos agricultores e trabalhadores.

Todavia, ainda existem pontos negativos, mas com possíveis soluções, como: em alguns casos há utilização de organismos geneticamente modificados, a competição de mercado com as plantações de alimentos, o aspecto funcional e estético pode não ser o mesmo das fibras já conhecidas e, se não associado a práticas de fabricação sustentáveis no processo de beneficiamento, a fibra deixa de ser de baixo impacto.

Outras estratégias de sustentabilidade são os consertos, alugueis e/ou trocas de produtos. Esta estratégia ocorre durante o uso do produto, e essa ação pode partir da marca ou por interesse do usuário. Consertar uma peça é como propor um redesign para o produto. Para Emidio e Souza $(2015$, p.32) no redesign "o conceito do produto continua o mesmo, porém os seus componentes são melhorados". Quando isso ocorre o ciclo de vida do produto é ampliado.

Atualmente algumas marcas oferecem junto da peça um botão ou acessório extra. Caso o que esteja na peça seja danificado, há um novo para ser trocado. Já outras marcas vendem junto com um produto, um kit de reparação que oferece, além de alguns componentes novos do produto, as ferramentas para o reparo.

No lado do consumidor, é crescente a busca por reparos e customizações caseiras. Na internet, inúmeros sites e blogs apresentam dicas de como reparar peças de roupa ou transformá-las, via vídeos ou editorias de DIY (do it yourself). A partir desses tutoriais, o público aprende o passo a passo e quais ferramentas ele precisa para fazer um conserto. As pessoas usam habilidades manuais para criar novas abordagens criativas em suas peças (GWILT, 2014).

$\mathrm{Na}$ estratégia de alugueis ou trocas de produtos também pode-se destacar os dois lados: as lojas e brechós que aceitam roupas usadas como moeda de troca, e de aluguel de produtos, e os consumidores, que usam aplicativos de troca/ venda e aluguel de produtos, organizam pequenas reuniões entre amigos para trocar peças de roupa as quais não usam mais, e em certas ocasiões buscam lojas de alugueis para evitar a compra de algumas peças, como bolsas, vestidos e sapatos (ANICET, BESSA e BROEGA, 2011).

Na moda há novos tipos de negócio todos os dias. Vale destacar as lojas que trabalham com a atitude de frear o consumo e gerar consciência no consumidor, pois essas lojas também ajudam a mudar os hábitos de consumo das pessoas, e o resultado é a crescente busca por consertar as roupas danificadas ou alugar produtos que não serão de uso diário. Pode-se então dizer que este é o ponto positivo dessa ferramenta sustentável.

O lado negativo é que ainda não há muito contato das marcas com essas ações, e por isso a responsabilidade acaba sendo inteiramente do consumidor. Gwilt (2014) diz que as marcas podem oferecer lojas ou áreas especializadas em conserto, e destaca o design pelo conserto, que prepara a peça para o desgaste, onde os locais mais sujeitos a estragos sejam de materiais de maior durabilidade ou até destacáveis, para serem trocados por novas partes.

Uma maneira de incluir mais a marca nesses tipos de ações é pela comunicação e ação como, por exemplo, criar uma ação de moeda de troca e informar o público a respeito da iniciativa. No inverno, por exemplo, algumas marcas arrecadam agasalhos e cobertores de qualquer marca em bom estado dos clientes, que ganham descontos nas peças das coleções atuais.

$\mathrm{Na}$ etapa de fim da vida pode-se aplicar a estratégia de sustentabilidade de devolução ou sistema de coleta. Os sistemas de coleta antecedem os processos de reciclagem e upcycling, 
pois consistem em recolher do mercado peças que chegaram no fim da vida de uso. Essas coletas são feitas em grandes centros ou ações de doação e, depois de recebidas, são levadas a um local onde é feito a triagem e limpeza.

Cada sistema de coleta tem um destino: na triagem as peças muito danificadas são incineradas, outra parte é destinada a reciclagem e processos de remanufatura, e as peças em boas condições são doadas. As doações que são feitas para países em desenvolvimento causam grande impacto social, pois descaracterizam a cultura e identidade local, e afeta a indústria do país que recebe essas peças (SALCEDO, 2014).

Não adianta coletar uma peça, retirando-a do seu destino final, o lixo, mas não ter um objetivo para o material. Neste caso a arrecadação acaba sendo um estorvo para a comunidade. Esse tipo de sistema de coleta funciona melhor quando uma empresa busca o retorno da peça, promovendo o processo de devolução para o fabricante, conhecido como take back systems.

Grandes marcas varejistas buscam o sistema de devolução, que aceita peças de qualquer marca e, em alguns casos, retribui o cliente com um cupom de desconto. A coleta é feita, geralmente, em caixas espalhadas nos pontos de vendas da marca ou de bastante circulação. As peças coletadas pelas marcas têm várias opções de destino como reutilização industrial do material ou reciclagem para geração de novos materiais (SALCEDO, 2014). Ambas estratégias se aplicam para a coleta de peças, mas se não acompanhadas a outras estratégias de sustentabilidade, acabam ocasionado grandes danos.

Ainda na etapa de fim da vida, é possível empregar a estratégia de reciclagem. A reciclagem, segundo Naime (2005), consiste em recolher, separar e processar materiais descartados, a fim de servir de matéria-prima para um novo processo industrial. A reciclagem de descartes têxteis pode ser de peças que chegaram no fim da vida ou de descartes têxteis gerados durante a produção das peças. Essa reciclagem é chamada de reciclagem de fibras, que pode ser por meio de processos químicos ou mecânicos (SALCEDO, 2014).

Para o processo de reciclagem de fibras as peças precisam estar desmontadas e sem aviamentos. Esse processo é difícil, pois as roupas passaram por processos de produções diferentes umas das outras e, portanto, cada uma é desmontada de forma diferente. Em seguida, esse material passa por processos químicos e mecânicos. Estes processos podem ser poluentes e consomem bastante energia, todavia Gwilt (2014) defende que é melhor, mesmo com os gastos extras, usar um material reciclado do que processar novas fibras, pois a base da fibra reciclada é um recurso que acabaria no lixo.

Vale salientar que a reciclagem funciona melhor em matérias de monofibra, ou seja, possuem em sua composição apenas um tipo de fibra, pois os tecidos mistos, se destroem durante o processo de reciclagem. Para a tecelagem de novos tecidos com fibras recicladas, as fibras de origem natural precisam ser misturadas com fibras virgens, pois o processo de reciclagem produz um fio mais frágil e o preço do produto sofre depreciação (GWILT, 2014).

Das várias estratégias de sustentabilidade apresentadas pode-se concluir que todas têm pontos positivos e negativos, mas que uma grande parte apresenta avanços e novas possibilidades para reverter os pontos negativos em positivos. A união de várias estratégias de sustentabilidade é que faz a diferença em um processo industrial, pois juntas, cada uma, em uma determinada etapa do ciclo de vida, geram um resultado eficaz. 


\section{CONSIDERAÇÕES FINAIS}

Baseado no objetivo proposto, a pesquisa em questão conseguiu delinear os assuntos de sustentabilidade, moda e design, para analisar a contribuição do upcycling para o design de moda sustentável.

O trabalho destacou a importância de se repensar o ciclo de vida do produto assim como o processo de upcycling, com a exposição de seus aspectos funcionais, etapas para elaboração e adição de estratégias sustentáveis, para uma possível aplicação em um desenvolvimento de produtos de moda, em projetos de design ou industrias têxteis. As características do processo de upcycling como alternativa para o desenvolvimento de novos produtos foram reconhecidos e apresentados; os aspectos positivos e negativos da aplicação do upcycling na indústria do vestuário em relação a outros processos que visam a sustentabilidade foram comparados e os exemplos de projetos de upcycling no design de moda identificados.

A pesquisa contribui para informar e refletir de que forma o desenvolvimento sustentável pode estar presente no mercado de moda e revela o upcycling como uma ferrrament em ascensão. As informações e os resultados obtidos através do presente estudo auxiliaram o autor no desenvolvimento de uma coleção upcycling para o segmento jeanswear feminino, para a conclusão do curso de Design de Moda da UNIVALI.

Sobretudo, analisar o processo de upcycling na área do design produz novos conhecimentos e caminhos para criar uma moda sustentável, ampliando o ciclo de vida de materiais descartados e agregando valor ao novo produto, o processo de upcycling passa a contribuir para a diminuição de descartes no meio ambiente, economia de materiais finitos, diminuição do uso de água e energia e inserção de valores éticos na sociedade.

\section{REFERÊNCIAS}

ABIT. 0 poder da moda Disponível em $<$ http://www.abit.org.br/conteudo/links/Poder_moda-cartilhabx.pdf>. Acesso em 19 set. 2016.

ANICET, Anne; BESSA, Pedro; BROEGA, Ana Cristina. Ações na área de moda em busca de um design sustentável. In: Anais do $7^{\circ}$ Colóquio de Moda, 2011. Disponível em: http://www.coloquiomoda.com.br/anais/anais/7-Coloquio-de-Moda_2011/GT11/GT/GT 89897_Acoes_na_area_da_moda_em_busca_de_um_design_sustentavel.pdf

ANICET, Anne; RUTHSCHILLING, Evelise Anicet. Relações entre moda e sustentabilidade. In: Anais do $9^{\circ}$ Colóquio de moda, 2012. Disposnível em: http://www.coloquiomoda.com.br/anais/anais/9-Coloquio-de-Moda_2013/ARTIGOS-DEGT/Artigo-GT-Moda-e-Sustentabilidade/Relacoes-entre-moda-e-sustentabilidade.pdf

BEZERRA, Germana Maria F.; MATOS, Chaiane K.; PESSOA, Juliana B. G. de P. O consumo no futuro. In: Anais do $7^{\circ}$. Colóquio de Moda, Paraná, 2011. Disponível em: http://www.coloquiomoda.com.br/anais/anais/7-Coloquio-de-

Moda_2011/GT02/Comunicacao-Oral/CO_89574O_consumo_no_Futuro_pdf

CAMARGO, Maristela; MARTELI, Leticia; MENEGUCCI, Franciele; VITO, Meriele. 
Resíduos têxteis: Análise sobre descarte e reaproveitamento nas indústrias de confecção. In: XI Congresso Nacional de Excelência em Gestão, 2015.

CAVALCANTI, Anna Luiza Moraes de Sá; SANTOS, Bruna Fischer. Um olhar do design a partir da abordagem do Upcycling. In: $5^{\circ}$ GAMPI Plural, 2015. Disponível em: http://pdf.blucher.com.br.s3-sa-east-1.amazonaws.com/designproceedings/gamp2015/IC_02 .pdf

EMIDIO, Lucimar de Fátima; SOUZA, Nádia Estefânia de. Diferenciação e sustentabilidade a partir do redesign de roupas de brechó: um modelo de estratégia produtiva. In: ModaPalavra e-periódico. Ano 9, 2015. Disponível em: http://www.revistas.udesc.br/index.php/modapalavra/article/view/6862

FLETCHER, Kate; GROSE, Lynda. Moda e Sustentabilidade: design para a mudança. São Paulo: Editora Senac, 2011.

GWILT, Alison. Moda sustentável: Um guia prático. São Paulo: Gustavo Gili, 2014.

LARA, Maria Claudia de; CARNEIRO, Stephanie Cristina; FABRI, Hélcio Prado. Upcycling: Uma nova perspectiva para produtos de moda. In: Anais $15^{\circ}$ Colóquio de Moda $8^{\mathrm{a}}$ Edição Internacional $2^{\circ}$ Congresso Brasileiro de Iniciação Científica em Design e Moda, 2015. Disponível em: http://www.coloquiomoda.com.br/anais/anais/11-Coloquio-deModa_2015/ARTIGOS-DE-GT/GT10-MODA-E-SUSTENTABILIDADE/GT-10Upcycling.pdf

LOPES, Luciane Dornbusch; PADILHA, Lucas da Rosa Mayeni Medeiros; SCHULTE, Neide Köhler. Logística reversa, reutilização e trabalho social na moda. In: ModaPalavra e-periódico Ano $\quad 7,2014.2$ Disponível http://www.revistas.udesc.br/index.php/modapalavra/article/view/5119/3317

LIPOVETSKY, Gilles. O Império do efêmero: a moda e seu destino nas sociedades modernas. São Paulo: Companhia das Letras, 2009.

NAIME, Roberto. Gestão de resíduos sólidos: uma abordagem prática. Novo Hamburgo: Feevale, 2005.

SALCEDO, Elena. Moda ética para um futuro sustentável. Barcelona: Gustavo Gili, 2014.

VALESE, Adriana et al. Faces do Design. São Paulo: Rosari, 2003.

VIALLI, Andréa. Upcycling, a nova fronteira da reciclagem. Disponível em: $<$ http://blogs.estadao.com.br/andrea-vialli/upcycling-a-nova-fronteira-da-reciclagem/>. Acesso em 18 out. 2016.

VINKEN, Barbara. Fashion Zeitgeist: Trends and Cycles in the Fashion. Nova Iorque: Bloomsbury Academic, 2005. 